\title{
FATORES DETERMINANTES DA ESTRUTURA DE CAPITAL DAS MAIORES EMPRESAS QUE ATUAM NO BRASIL
}

\author{
DETERMINANT FACTORS OF CAPITAL STRUCTURE \\ FOR THE LARGEST COMPANIES ACTIVE IN BRAZIL
}

\author{
GIOVANI ANTONIO SILVA BRITO \\ Mestre em Controladoria e Contabilidade \\ pela Faculdade de Economia, Administração e Contabilidade \\ da Universidade de São Paulo - Campus Capital \\ E-mail: giovanibrito@yahoo.com.br
}

- LUIZ J. CORRAR

Professor Doutor do Departamento de Contabilidade e Atuária da Faculdade de Economia, Administração e Contabilidade da Universidade de São Paulo - Campus Capital E-mail: ljcorrar@usp.br

FLÁVIO DONIZETE BATISTELLA

Professor Assistente do Departamento de Contabilidade

da Faculdade de Economia, Administração e Contabilidade

da Universidade de São Paulo - Campus Ribeirão Preto

E-mail: batistella@fearp.usp.br

\section{RESUMO}

Estrutura de capital é um tema ainda controverso em teoria de finanças. Desde a discussão entre a teoria tradicional, que defende a existência de uma estrutura de capital ótima que leva à maximização do valor da empresa, e a proposta por Modigliani e Miller (1958), que considera que o valor da empresa não é afetado pela forma como ela é financiada, diversos estudos empíricos têm sido realizados com o objetivo de identificar os fatores que explicam a forma como as empresas se financiam. Esta pesquisa analisa a estrutura de capital das maiores empresas que atuam no Brasil, investigando a relação entre o nível de endividamento e os fatores apontados pela teoria como seu determinante. O estudo é baseado em dados contábeis extraídos das demonstrações financeiras de empresas de capital aberto e de empresas de capital fechado. A técnica estatística utilizada no estudo é a regressão linear múltiplạ. Os resultados indicam que os fatores risco, tamanho, composição dos ativos e crescimento são determinantes da estrutura de capital das empresas, enquanto que o fator rentabilidade não é determinante. Os resultados, também, mostram que o nível de endividamento da empresa não é afetado pelo fato de ela ser de capital aberto ou de capital fechado.

Palavras-chave: Finanças corporativas, Estrutura de capital, Endividamento, Regressão linear múltipla.

\section{ABSTRACT}

Capital structure is still a still controversial issue in finance theory. Since the discussion between traditional theory, which asserts the existence of an optimal capital structure that maximizes the firm's value, and Modigliani and Miller's theory (1958), which considers that the value of a firm is unaffected by how it is financed, many empirical studies have been carried out to identify the factors that explain how a firm finances itself. This research analyses the capital structure of the largest firms in Brazil and investigates the relationship between the leverage ratio and the factors indicated by theory as determinant. The study is based on accounting data extracted from the financial statements of publicly traded and private companies. Multiple linear regression was applied as a statistical technique. The results indicate that risk, firm size, fixed assets and growth are determinants of the firms' capital structure, while profitability is not a determinant factor. The results also show that the firms' leverage is unaffected by whether a firm is publiclytraded or private.

Keywords: Corporate finance, Capital structure, Debt ratio, Multiple Linear regression. 


\section{INTRODUÇÃO}

Estrutura de capital é um tema ainda bastante controverso em teoria de finanças. Muito embora o assunto venha sendo discutido nos meios acadêmicos há cerca de 50 anos, a heterogeneidade das evidências empíricas leva a crer que o tema não foi completamente explorado.

O trabalho clássico de Modigliani e Miller (1958) propôs que, sob certos pressupostos, a estrutura de capital é irrelevante para o valor da empresa. A proposição contrapunha a teoria convencional, que defendia a existência de uma estrutura de capital ótima, a qual minimizaria o custo de capital da empresa e maximizaria o seu valor.

Essa discussão deu origem a um grande esforço de pesquisa centrado na busca dos aspectos que explicam a forma como as empresas se financiam. Os trabalhos passaram a levar em conta as imperfeições existentes no mercado, como impostos, custos de falência, custos de agência e assimetria de informações, formando um conjunto de novas teorias sobre estrutura de capital.

Baseados nessas teorias, estudos empíricos realizados principalmente no mercado norte-americano sugerem a existência de uma série de fatores que influenciariam o nível de endividamento das empresas. No Brasil, diversas pesquisas desenvolvidas nos últimos anos, igualmente, têm buscado evidências empíricas acerca dos fatores que determinam a estrutura de capital das empresas. No entanto, os resultados alcançados por esses trabalhos não têm sido homogêneos.
Destaque-se que as teorias sobre a estrutura de capital das empresas foram desenvolvidas em contextos econômicos bastante diferentes dos observados em países em desenvolvimento como o Brasil. Em razão disso, a aplicação dessas teorias deve ser feita à luz das peculiaridades do nosso mercado.

A presente pesquisa analisa as características da estrutura de capital das maiores empresas que atuam no Brasil, investigando a relação entre o nível de endividamento e os fatores apontados pela teoria como seu determinante. $\mathrm{O}$ objetivo do estudo é identificar os fatores que explicam a forma como as maiores empresas no Brasil se financiam. O estudo é feito a partir do banco de dados da Fipecafi - Fundação Instituto de Pesquisas Contábeis, Atuariais e Financeiras ${ }^{1}$, que contém informações sobre as 500 maiores empresas que atuam no país. A técnica estatística utilizada é a regressão linear múltipla.

O restante do trabalho está organizado da seguinte forma: na seção 2 é feita uma revisão dos conceitos e principais correntes teóricas sobre estrutura de capital; na seção 3 são apresentadas as hipóteses de pesquisa e caracterizados os dados e variáveis utilizadas, bem como os procedimentos estatísticos realizados; a seção 4 exibe os resultados da pesquisa e, por fim, a seção 5 apresenta as considerações finais.

\section{REFERENCIAL TEÓRICO}

Um dos temas centrais em teoria de finanças corporativas diz respeito à estrutura de capital das empresas. Estrutura de capital refere-se à forma como as empresas utilizam capital próprio e capital de terceiros para financiar os seus ativos. Em linhas gerais, os capitais próprios são os recursos fornecidos pelos sócios ou acionistas, enquanto os capitais de terceiros envolvem os recursos obtidos por meio de dívidas.

Estrutura de capital é um assunto que vem sendo intensamente discutido pelos pesquisadores da área financeira, especialmente a partir do trabalho de Modigliani e Miller (1958). A questão principal que envolve o tema é se a forma como a empresa é financiada influencia ou não o seu valor. Podem ser identificadas duas grandes correntes teóricas sobre estrutura de capital: a tradicionalista (teoria convencional), representada principalmente por Durand (1952), e a proposta por Modigliani e Miller (1958).

A teoria tradicional defende que a estrutura de capital influencia o valor da empresa. Segundo essa corrente, o custo do capital de terceiros mantém-se estável até um determinado nível de endividamento, a partir do qual se eleva devido ao aumento do risco de falência. Como o custo de capital de terceiros é inferior ao custo do capital próprio, a empresa deveria se endividar até o ponto em que o seu custo de capital total atingisse um patamar mínimo. Esse ponto representaria a estrutura de capital ótima, que levaria à maximização do valor da empresa.

Em contraposição à teoria convencional e baseados em um conjunto de pressupostos bastante restritivos, Modigliani e Miller (1958) argumentaram que a forma com que a empresa é financiada é irrelevante para o seu valor. Para os autores, o custo de capital da empresa é o mesmo para qualquer nível de endividamento e, portanto, não haveria uma estrutura de capital ótima. Dessa forma, o valor de uma empresa não é função da forma como ela é financiada, mas sim dos fluxos de caixa por ela gerados e do seu risco.

A partir dessa discussão, diversas pesquisas passaram a ser realizadas com o objetivo de identificar os fatores que explicam a forma com que as empresas se financiam, dando origem à teoria moderna de estrutura de capital. Muitos trabalhos avaliaram a questão considerando as imperfeições existentes no mercado, como impostos, custos de falência, custos de agência e assimetria de informações. 
Em trabalho posterior, os próprios Modigliani e Miller (1963) avaliaram o efeito dos impostos na estrutura de capital das empresas. Os autores exploraram a questão do benefício fiscal gerado pela utilização de dívidas, decorrente do fato de os juros serem dedutíveis na apuração do imposto de renda das empresas. Em conseqüência desse benefício, um maior nível de endividamento levaria a um aumento do seu valor.

Entretanto, o crescimento das dívidas pressiona os fluxos de caixa da empresa em razão da obrigação com pagamento de juros e amortização do principal, levando a uma maior probabilidade de falência e, conseqüentemente, à elevação do custo de capital de terceiros. Assim, a partir de um certo nível de endividamento, o benefício fiscal decorrente da utilização das dívidas é anulado pelo aumento do risco de falência. Entre as pesquisas que consideraram a existência de custos de falência, estão as de Scott (1976), Miller (1977) e DeAngelo e Masulis (1980).

A utilização de uma estrutura mais endividada dá origem a conflitos de interesse entre credores, acionistas e administradores, uma vez que os credores fornecem fundos às empresas sem ter controle completo sobre a aplicação desses recursos. Uma das possíveis formas de conflito envolve a alteração da postura dos acionistas em relação ao risco. Como os acionistas se apropriam de todo o lucro residual após o pagamento do custo fixo das dívidas e sua responsabilidade está limitada ao capital aportado, há um incentivo para que prefiram investimentos de maior risco, sobretudo quando a empresa enfrenta dificuldades financeiras. Para se defender desse comportamento, os credores incorporam custos de agência aos encargos financeiros cobrados nos empréstimos. Os conflitos entre grupos que procuram beneficiar-se dos recursos das empresas foram estudados, inicialmente, por Jensen e Meckling (1976).

Myers e Majluf (1984) analisaram a questão da assimetria de informações nas decisões de investimento das empresas. A assimetria informacional decorre do fato de os administradores internos deterem informações sobre as oportunidades de investimento da empresa que os investidores externos não possuem. Harris e Raviv (1991) destacaram que a estrutura de capital pode ser usada como sinalizador aos investidores externos das informações detidas pelos administradores, reduzindo a assimetria de informações.

De forma simplificada, uma empresa pode financiar suas novas oportunidades de investimento por meio de capital próprio ou capital de terceiros. A opção por financiar o investimento por meio de dívidas sinaliza ao mercado que a administração acredita que as ações da empresa estão subavaliadas. Essa decisão representa um sinal positivo ao mercado, pois a riqueza produzida pelo novo investimento será absorvida apenas pelos atuais acionistas. Segundo essa teoria, para evitar uma sinalização negativa ao mercado e reduzir o seu valor, as empresas mantêm uma reserva de capacidade de endividamento para utilização em futuros investimentos.
A partir das pesquisas sobre assimetria informacional, Myers (1984) propôs a teoria do Pecking Order, que considera a existência de uma hierarquia nas fontes de financiamento, ou seja, assume-se que as empresas priorizam o uso de uma fonte de recursos em relação à outra. Para essa teoria, as empresas em geral preferem financiar seus investimentos por meio de recursos internos (retenção de lucros). Caso esses recursos não sejam suficientes, a segunda opção é o financiamento por meio de dívidas e, por fim, se ainda houver a necessidade de recursos, são emitidas novas ações.

As teorias sobre estrutura de capital foram construídas em conjunto com o desenvolvimento de uma série de pesquisas empíricas que tiveram como objetivo identificar os fatores que determinam a estrutura de capital das empresas. Entre esses estudos, estão os de Toy et al. (1974), Ferri e Jones (1979), Bradley, Jarrel e Kim (1984), Titman e Wessels (1988), Klock e Thies (1992) e Rajan e Zingales (1995).

Destaque-se que o desenvolvimento das teorias sobre estrutura de capital ocorreu em ambientes econômicos e institucionais bastante diferentes do contexto brasileiro. Esses mercados apresentam determinadas características que não se verificam em economias em desenvolvimento como o Brasil. Entre essas características, Assaf Neto (2003, p.414) destaca as taxas de juros homogêneas, o equilíbrio entre agentes econômicos superavitários e deficitários, a ausência de controles artificiais de mercado e a inexistência de níveis de inflação relevantes.

Ao contrário das economias desenvolvidas, o mercado brasileiro apresenta certas ineficiências que impactam, diretamente, nas decisões de financiamento das empresas. Entre essas imperfeições, destacam-se o mercado de capitais restrito, a elevada concentração do controle acionário das empresas e a forte restrição de fontes de capital de terceiros de longo prazo. Adicionalmente, as elevadas taxas de juros tornam os custos de financiamento bastante significativos, fazendo com que as empresas no Brasil apresentem baixos níveis de endividamento.

Outra característica do mercado brasileiro é o fato de o custo de capital de terceiros não ser função apenas do risco do tomador, mas também da natureza da fonte de financiamento. Em razão disso, determinadas linhas de crédito de longo prazo direcionadas a investimentos específicos têm custo financeiro inferior a linhas de curto prazo, cujo risco de crédito para o credor normalmente é menor.

Esses aspectos tornam ainda mais difícil o estudo das formas de financiamento das empresas no Brasil. Nesse contexto, diversos estudos empíricos têm sido empreendidos para se avaliar quais os fatores que determinam a estrutura de capital das empresas brasileiras, como os de Tedeschi (1997), Kayo (1997), Martelanc (1998), Gomes e Leal (2000), Moreira e Puga (2000), Pereira (2000), Perobelli e Famá (2002), Sallum (2004) e Schmitt (2004). 


\section{MÉTODO DE PESOUISA}

Para atender ao propósito do estudo de identificar os fatores que explicam a forma como as maiores empresas que atuam no Brasil se financiam, foram testadas dez hipóteses de pesquisa envolvendo variáveis que potencialmente determinam a estrutura de capital das firmas. As hipóteses testadas foram construídas com base nas teorias de estrutura de capital e em pesquisas empíricas realizadas por outros autores, considerando também a disponibilidade de dados.

\subsection{Hipóteses de Pesquisa}

As hipóteses de pesquisa envolvem seis fatores considerados como potenciais explicativos da estrutura de capital das empresas. Os fatores são: rentabilidade, risco, tamanho, composição dos ativos, crescimento e tipo de capital (aberto ou fechado), conforme detalhado a seguir:

a) Rentabilidade: segundo a teoria do Pecking Order, há uma hierarquia nas fontes de financiamento das empresas, que preferem financiar seus investimentos por meio da retenção de lucros, em detrimento a recursos de terceiros e a capitais novos dos acionistas. Assim, a capacidade de gerar lucros da empresa influenciaria sua estrutura de capital, à medida que as firmas que detenham maior fonte de recursos próprios para se auto-financiar deverão recorrer menos ao uso de dívidas. Espera-se, portanto, que as empresas mais rentáveis sejam menos endividadas. Hipótese 1: há uma relação negativa entre rentabilidade e endividamento.

b) Risco: as teorias dos custos de falência e dos custos de agência sugerem que o fator risco tenha influência na estrutura de capital das empresas. Firmas cujos negócios apresentam elevado risco terão maior probabilidade de seus fluxos de caixa serem insuficientes para honrar as obrigações com os credores e, conseqüentemente, poderão se endividar menos. Assim, espera-se que as empresas com maior risco de negócio sejam menos endividadas. Hipótese 2: há uma relação negativa entre risco e endividamento.

c) Tamanho: de acordo com a teoria dos custos de falência, empresas grandes, normalmente, são mais diversificadas do que empresas pequenas, estando menos sujeitas a dificuldades financeiras e possuindo custos de falência menores. Em razão disso, sua capacidade de endividamento é maior do que a das empresas pequenas. Adicionalmente, uma característica do mercado brasileiro é que as grandes empresas têm maior acesso a crédito de longo prazo do que as pequenas empresas, sobretudo por meio de Bancos de Desenvolvimento.

Como essas operações, geralmente, possuem custo financeiro inferior às linhas de curto prazo utilizadas pelas empresas menores, devido às taxas subsidia- das, há um incentivo para que as grandes empresas se endividem mais. Diante desses aspectos, esperase que as grandes empresas sejam mais endividadas e tenham proporcionalmente mais dívidas de longo prazo, e que as pequenas empresas sejam menos endividadas e tenham proporcionalmente mais dívidas de curto prazo.

Hipótese 3: há uma relação positiva entre tamanho e endividamento total.

Hipótese 4: há uma relação positiva entre tamanho e endividamento de longo prazo.

Hipótese 5: há uma relação negativa entre tamanho e endividamento de curto prazo.

d) Composição dos Ativos: a teoria dos custos de falência considera que as empresas que dispõem de ativos fixos para oferecer aos credores como garantia das dívidas têm maior capacidade de endividamento, uma vez que esses ativos podem ser vendidos em caso de insolvência, reduzindo os custos de falência. As teorias de informações assimétricas e custos de agência sugerem também que os credores preferem emprestar para empresas que detenham ativos fixos, pois a utilização de dívidas garantidas diminui a assimetria informacional entre administradores e credores, além de reduzir a propensão dos administradores a investir de maneira subótima, como, por exemplo, em projetos de risco elevado. Assim, espera-se que as empresas com maior ativo fixo sejam mais endividadas e tenham proporcionalmente mais dívidas de longo prazo e menos dívidas de curto prazo.

Hipótese 6: há uma relação positiva entre ativo permanente e endividamento total.

Hipótese 7: há uma relação positiva entre ativo permanente e endividamento de longo prazo.

Hipótese 8: há uma relação negativa entre ativo permanente e endividamento de curto prazo.

e) Crescimento: a teoria dos custos de agência considera que as empresas em crescimento possuem maior flexibilidade para escolher seus investimentos e, por isso, têm custos de agência também maiores. Além disso, empresas com elevadas taxas de crescimento possuem alto custo de falência, pois parte substancial do seu valor está atrelado a expectativas futuras de lucro e não a ativos que possam ser liquidados em caso de dificuldades financeiras. Esses argumentos indicam que empresas em crescimento deveriam ser menos endividadas.

Hipótese 9: há uma relação negativa entre crescimento e endividamento.

f) Tipo de Capital: empresas de capital aberto têm a opção de financiar seus projetos de investimento 
por meio da captação de recursos junto a investidores no mercado de capitais. Em vista da escassez de linhas de crédito de longo prazo no Brasil, o mercado de capitais se torna de grande importância para a expansão das empresas. Assim, espera-se que as empresas de capital aberto sejam menos endividadas do que as de capital fechado.

Hipótese 10: as empresas de capital aberto são menos endividadas do que as de capital fechado.

\subsection{Dados}

O estudo é feito com base no banco de dados da Fipecafi - Fundação Instituto de Pesquisas Contábeis, Atuariais e Financeiras, que contém informações contábeis das 500 maiores empresas que atuam no Brasil, segundo o critério de receita anual de vendas. A informação se a empresa é de capital aberto ou de capital fechado foi obtida junto à Comissão de Valores Mobiliários (CVM).

O período considerado na pesquisa compreende os anos de 1998 a 2002 (cinco exercícios). Neste estudo, cada conjunto de dados relativos a uma determinada empresa em um ano específico é chamado de observação. Como algumas empresas não dispunham dos dados referentes a todos os anos considerados na pesquisa, o banco de dados final, utilizado nos testes estatísticos, englobou 1.724 observações e 466 empresas: 185 são de capital aberto e 281 de capital de fechado. Para melhorar a qualidade dos resultados obtidos, foram utilizados os dados contábeis ajustados aos efeitos inflacionários.

\subsection{Variáveis}

As variáveis utilizadas nos procedimentos estatísticos foram definidas com base nas hipóteses de pesquisa construídas. As variáveis dependentes referem-se à estrutura de capital das empresas e são representadas por índices de endividamento calculados a partir dos dados contábeis. Foram calculados quatro indicadores de endividamento, sendo um como medida de endividamento de curto prazo (CIRC/AT), um como medida de endividamento de longo prazo (ELP/AT) e dois como medidas de endividamento total (EXIG/AT) e (EXIG/PL), o primeiro em relação ao ativo total e o segundo em relação ao patrimônio líquido. As variáveis dependentes são assim calculadas:

CIRC/AT: $Y_{1}=\frac{\text { Passivo circulante }}{\text { Ativo total }}$
ELP/AT: $Y_{2}=\frac{\text { Exígivel a longo prazo }}{\text { Ativo total }}$

EXIG/AT:

$$
Y_{3}=\frac{\text { Passivo circulante }+ \text { Exígivel a longo prazo }}{\text { Ativo total }}
$$

EXIG/PL:

$$
Y_{4}=\frac{\text { Passivo circulante }+ \text { Exígivel a longo prazo }}{\text { Patrimônio líquido }}
$$

As variáveis independentes representam os fatores potencialmente determinantes da estrutura de capital das empresas. Há diversas formas de essas variáveis serem operacionalizadas. Como não foi identificado um padrão na literatura, foram adotadas formas de cálculo frequentemente utilizadas em pesquisas empíricas sobre esse tema.

As variáveis que representam os fatores rentabilidade (RENT), risco (RISC), tamanho (TAM), composição dos ativos (PERM), crescimento (CRESC) e tipo de capital (CAP) são assim definidas:

RENT: $X_{1}=\frac{\text { Lucro líquido }}{\text { Patrimônio líquido }}$

RISC: $X_{2}=$ Desvio padrão de rentabilidade

TAM: $X_{3}=$ LnVendas

PERM: $X_{4}=\frac{\text { Ativo permanente }}{\text { Ativo total }}$

CRESC: $X_{5}=\frac{\text { Vendas }_{t}}{\text { Vendas }_{t-1}}$

CAP: $X_{6}=1$ para capital aberto e 0 para capital fechado (váriavel dummy)

\subsection{Procedimentos Estatísticos}

A técnica estatística aplicada no estudo foi a regressão linear múltipla, pelo método dos mínimos quadrados ordinários (MQO). Como as variáveis testadas se referem a diferentes empresas e diversos períodos, utilizou-se a técnica pooling, que combina dados de seção transversal (cross-section) e dados em série temporal, conforme proposto por Wooldridge (2003). O estudo envolveu quatro regressões, uma para cada medida de endividamento definida como variável dependente. O modelo matemático utilizado é, assim, definido:

$$
E_{n} d_{i}=\alpha+\beta_{1} R E N T_{i}+\beta_{2} R_{S I S C_{i}}+\beta_{3} T A M_{i}+\beta_{4} P E R M_{i}+\beta_{5} \operatorname{CRESC}_{i}+\beta_{6} C A P_{i}+\mu
$$

em que: $E N D_{i}$ é o endividamento da empresa $i$ no ano $t ; \alpha$ é o intercepto da reta; $\beta$ são os coeficientes angulares; RENT, RISC $_{i}$, TAM $M_{i}$, PERM $_{i}$, CRESC e CAP são as variáveis independentes da empresa $i$ no ano $t$ e $\mu$ é o termo de erro.

\subsection{Validação dos Pressupostos do Modelo de Regressão}

A validação dos pressupostos assumidos pelo modelo de regressão foi efetuada por meio da aplicação de testes quanto à independência dos resíduos, homocedasticidade, normalidade dos resíduos e ausência de multicolinearidade. 
a) Independência dos resíduos: o pressuposto de independência dos resíduos foi avaliado por meio do Teste de Durbin-Watson. O teste de Durbin-Watson mede a correlação entre cada termo de erro e o termo de erro da observação imediatamente anterior. $A$ estatística de Durbin-Watson (DW) é definida como:

$$
D W=\frac{\sum\left(u_{t}-u_{t-1}\right)^{2}}{\sum u_{t}^{2}}
$$

em que: $u_{t}$ é o termo de erro no período $t$ e $u_{t-1}$ é o termo de erro no período $t-1$. Estatísticas de Durbin-Watson próximas a 2 indicam a independência dos resíduos do modelo de regressão. A Tabela $1 \boldsymbol{O}$ apresenta as estatísticas obtidas com o teste de Durbin-Watson.

b) Homocedasticidade: o pressuposto da homocedasticidade (variância constante dos resíduos) foi avaliado por meio do Teste de Pesaran-Pesaran. O teste detecta a presença de heterocedasticidade com base nos resultados da regressão em que a variável dependente é o valor dos quadrados dos resíduos e a variável independente é o valor estimado da variável dependente original. Se houver uma relação significante entre as variáveis, rejeita-se a hipótese nula de ausência de heterocedasticidade. A Tabela 20 apresenta os valores do $F$ de significação das regressões do teste de Pesaram-Pesaram.

Os resultados do teste indicam a presença de heterocedasticidade nos resíduos do modelo. Wooldridge (2003) comenta que a heterocedasticidade é comum em dados de seção transversal, uma vez que geralmente as observações que compõem a amostra não são homogêneas. No caso de empresas, por exemplo, a variabilidade nos tamanhos e setores de atuação é uma das possíveis causas de heterocedasticidade.

Como na presença de heterocedasticidade os estimadores gerados pelo método dos mínimos qua- drados ordinários deixam de ser eficientes, os testes de hipótese e os intervalos de confiança das estimativas ficam comprometidos. Para solucionar o problema, foram utilizados os estimadores corrigidos pelo método de White (1980).

c) Normalidade dos resíduos: o pressuposto da normalidade dos resíduos foi avaliado por meio do teste de Kolmogorov-Smirnov. O teste de Kolmogorov-Smirnov avalia se os valores de uma amostra podem ser considerados como provenientes de uma população com determinada distribuição teórica. O teste é realizado calculando-se a distância euclidiana máxima (D) entre a função de distribuição empírica acumulada e a função de distribuição acumulada teórica que se deseja testar.

A estatística do teste de Kolmogorov-Smirnov pode ser, assim, definida:

$$
D_{n}=\max \left|F_{e}-F_{o}\right|
$$

em que: $F_{e}$ é freqüência relativa acumulada esperada e $F_{o}$ é a freqüência relativa acumulada observada. Se a estatística teste for superior ao valor crítico, rejeita-se a hipótese nula de que os dados seguem a distribuição especificada. A Tabela 30 apresenta as estatísticas do teste de Kolmogorov-Smirnov.

Como o valor crítico ao nível de significância de $5 \%$ é de 0,033 , não se rejeita a hipótese de que os resíduos das regressões que tiveram como variáveis dependentes CIRC/AT, ELP/AT e EXIG/AT seguem uma distribuição normal de probabilidade. Entretanto, os valores dos resíduos da regressão que teve como variável dependente EXIG/PL apresentaram desvios significativos em relação aos valores esperados, não podendo ser considerados como normalmente distribuídos.

Como nesse caso houve violação do pressuposto do modelo, a regressão envolvendo o indicador de endividamento EXIG/PL foi excluída da pesquisa. Ressalte-se que

Tabela 1 Teste de Durbin-Watson

\begin{tabular}{c|c} 
Variável Dependente & Estatística Durbin-Watson \\
\hline CIRC/AT & 1,989 \\
\hline ELP/AT & 1,968 \\
\hline EXIG/AT & 1,932 \\
\hline EXIG/PL & 1,932
\end{tabular}

Tabela 2 | Teste de Pesaram-Pesaram

\begin{tabular}{c|c} 
Variável Dependente Orig. & F de Significação \\
CIRC/AT & 0,000013 \\
\hline ELP/AT & 0,000000 \\
\hline EXIG/AT & 0,000001 \\
\hline EXIG/PL & 0,000000
\end{tabular}


Tabela 3 - Teste de Kolmogorov-Smirnov

\begin{tabular}{c|c} 
Variável Dependente & Desvio Máximo \\
\hline CIRC/AT & 0,029 \\
\hline ELP/AT & 0,031 \\
\hline EXIG/AT & 0,017 \\
\hline EXIG/PL & 0,266
\end{tabular}

Tabela 4 | Matriz de Correlação das Variáveis Independentes

\begin{tabular}{l|c|c|c|c|c} 
& RENT & RISC & TAM & PERM & CRESC \\
RENT & 1 & & & & \\
\hline RISC & $-0,446$ & 1 & & & \\
\hline TAM & 0,020 & 0,042 & 1 & & \\
\hline PERM & $-0,009$ & $-0,062$ & 0,129 & 1 & \\
\hline CRESC & 0,072 & $-0,008$ & 0,016 & 0,015 & 1
\end{tabular}

não houve perda de informação, uma vez que as variáveis EXIG/AT e EXIG/PL têm o mesmo significado econômico, sendo indicadores do endividamento global da empresa.

d) Multicolinearidade: a presença de multicolinearidade entre os regressores do modelo foi avaliada por meio da matriz de correlação das variáveis indepen- dentes. A matriz de correlação apresentada na Tabela 40 mostra que as variáveis independentes não são altamente correlacionadas. As variáveis que se apresentaram mais correlacionadas foram rentabilidade (RENT) e risco (RISC), as quais têm coeficiente de correlação de -0,446.

\section{RESULTADOS}

\subsection{Estatísticas Descritivas}

A Tabela 50 apresenta as médias e o desvios-padrão dos índices de endividamento (variáveis dependentes) e dos fatores rentabilidade, risco, tamanho, composição dos ativos e crescimento (variáveis independentes), em relação às empresas de capital aberto, às empresas de capital fechado e ao conjunto total de empresas analisadas.

As medidas obtidas evidenciam que o endividamento total médio (EXIG/AT) das maiores empresas que atuam no Brasil é de 52,9\%. As empresas de capital aberto apresentam endividamento total médio um pouco inferior $(51,8 \%)$ ao das empresas de capital fechado $(53,7 \%)$.

De uma forma geral, as empresas endividam-se mais com recursos de curto prazo (CIRC/AT $=30,3 \%)$, do que com recursos de longo prazo (ELP/AT $=22,6 \%$ ), possivelmente devido à escassez de créditos de longo prazo do mercado brasileiro. Essa característica é ainda mais evidente nas empresas de capital fechado, que têm endividamento de curto prazo (CIRC/AT) de 33,4\% e endividamento de longo prazo (ELP/AT) de 20,3\%. As empresas de capital aberto, por sua vez, endividam-se com recursos de curto prazo e de longo prazo em proporções semelhantes (CIRC/ $A T=26,0 \%$ e ELP/AT $=25,8 \%$ ).

Considerando que os dados contábeis estão ajustados aos efeitos inflacionários, a rentabilidade média sobre o patrimônio líquido das empresas foi negativa $(-0,7 \%)$, apesar de as empresas terem apresentado crescimento médio nas vendas da ordem de 7,6\%. Comparando as empresas de capital aberto com as empresas de capital fechado, pode-se observar que o desempenho das primeiras (RENT $=-2,9 \%$ ) foi inferior ao das últimas (RENT $=0,8 \%$ ).

As estatísticas mostram, também, que as empresas de capital aberto têm maior variabilidade nos índices de rentabilidade (RISC $=17,7 \%$ ) do que as de capital fechado (RISC $=16,4 \%)$. Além disso, as primeiras são em média maiores $($ TAM $=14,144)$ dos que as últimas (TAM = 13,723). Em relação à composição dos ativos, as empresas de capital aberto têm em sua estrutura de ativos uma proporção de ativos permanentes bastante superior (PERM $=60,3 \%)$ à das empresas de capital fechado (PERM $=45,5 \%)$.

\subsection{Coeficientes Estimados}

A Tabela $6 \bullet$ apresenta os modelos de regressão obtidos para cada variável dependente, incluindo os coeficientes estimados, as estatísticas $t$ e os coeficientes de determinação ajustados ( $R^{2}$ ajustado). A estatística $t$ avalia a significância estatística de cada parâmetro estimado e o coeficiente de determinação ajustado ( $R^{2}$ ajustado) indica o poder explicativo da regressão.

Os resultados mostram que os fatores que mais explicam os índices de endividamento das empresas são risco (RISC) e composição dos ativos (PERM), cujos coeficientes são estatisticamente significantes nas três regressões. Os fatores tamanho (TAM) e crescimento (CRESC) são deter- 
Tabela 5 Estatísticas Descritivas

\begin{tabular}{|c|c|c|c|c|c|c|}
\hline \multirow{2}{*}{ Variável } & \multicolumn{2}{|c|}{ Capital Aberto } & \multicolumn{2}{|c|}{ Capital Fechado } & \multicolumn{2}{|c|}{ Total de Empresas } \\
\hline & Média & Desvio-Padrão & Média & Desvio-Padrão & Média & Desvio-Padrão \\
\hline CIRC/AT & 0,260 & 0,141 & 0,334 & 0,196 & 0,303 & 0,179 \\
\hline ELP/AT & 0,258 & 0,173 & 0,203 & 0,169 & 0,226 & 0,173 \\
\hline EXIG/AT & 0,518 & 0,203 & 0,537 & 0,213 & 0,529 & 0,209 \\
\hline RENT & $-0,029$ & 0,527 & 0,008 & 0,537 & $-0,007$ & 0,533 \\
\hline RISC & 0,177 & 0,328 & 0,164 & 0,338 & 0,170 & 0,334 \\
\hline TAM & 14,144 & 0,824 & 13,723 & 0,686 & 13,900 & 0,775 \\
\hline PERM & 0,603 & 0,189 & 0,455 & 0,226 & 0,517 & 0,224 \\
\hline CRESC & 0,074 & 0,212 & 0,077 & 0,222 & 0,076 & 0,218 \\
\hline
\end{tabular}

Tabela 6 | Resultados dos Modelos de Regressão

Painel A: Modelo de Regressão para a Variável CIRC/AT

\begin{tabular}{l|c|c|c} 
Variável Independente & Coeficiente Estimado & Estatística t & $\mathbf{R}^{2}$ Ajustado \\
\hline RENT & $-0,0002$ & 1,355 & \\
\hline RISC* & 0,0006 & 2,981 & \\
\hline TAM & 0,0012 & 0,163 & \\
\hline PERM* & $-0,4780$ & $-18,687$ & 0,359
\end{tabular}

Painel B: Modelo de Regressão para a Variável ELP/AT

\begin{tabular}{l|c|c|c} 
Variável Independente & Coeficiente Estimado & Estatística t & $\mathbf{R}^{2}$ Ajustado \\
\hline RENT & 0,0001 & 0,717 & \\
\hline RISC* & 0,0012 & 4,809 & \\
\hline TAM* $^{*}$ & 0,0293 & 4,095 & \\
\hline PERM $^{*}$ & 0,2180 & 9,401 & 0,181
\end{tabular}

Painel C: Modelo de Regressão para a Variável EXIG/AT

\begin{tabular}{l|c|c|c} 
Variável Independente & Coeficiente Estimado & Estatística t & $\mathbf{R}^{\mathbf{2}}$ Ajustado \\
\hline RENT & $-0,0001$ & 0,410 & \\
\hline RISC* & 0,0019 & 6,548 & \\
\hline TAM $^{*}$ & 0,0305 & 3,703 & \\
\hline PERM $^{*}$ & $-0,2600$ & $-9,004$ & 0,229
\end{tabular}

Nota: utilizou-se MOO, com correção de heterocedasticidade pelo estimador consistente de White.

* variáveis significantes a $5 \%$.

minantes dos endividamentos de longo prazo (ELP/AT) e total (EXIG/AT), não sendo significantes para o endividamento de curto prazo. Não são significantes para quaisquer dos indicadores de endividamento considerados os fatores rentabilidade (RENT) e tipo de capital (CAP).

A regressão com a variável dependente CIRC/AT foi a que apresentou o maior coeficiente de determinação ajustado $\left(R^{2}\right.$ ajustado $\left.=0,359\right)$, o que indica que os fatores estudados explicam mais a variação do endividamento de curto prazo do que a variação dos endividamentos de longo prazo e total. Apesar de esse coeficiente sugerir que outras variáveis explicativas ainda possam ser incluídas no modelo, a regressão apresentou um poder explicativo superior ao geralmente obtido nos estudos dessa natureza do Brasil.

\subsection{Avaliação das Hipóteses de Pesquisa}

A partir dos coeficientes estimados pela regressão, pode-se avaliar a relação existente entre os diversos indica- 
dores de endividamento (variáveis dependentes) e cada um dos seus potenciais fatores explicativos (variáveis independentes). Essa relação pode ser positiva ou negativa, o que indica se uma variação nos fatores explicativos é acompanhada por uma variação nos índices de endividamento no mesmo sentido ou em sentido oposto. A análise permite que as hipóteses de pesquisa construídas sejam ou não rejeitadas.

A Tabela 70 mostra o sinal das relações esperadas e observadas entre as variáveis dependentes e independentes. O sinal "+" indica uma relação positiva, o sinal "-" indica uma relação negativa e o "NS" indica uma relação não significante estatisticamente.

As análises estatísticas mostram que as conclusões precisam ser tomadas com bastante cautela. Os resultados indicam que a rentabilidade não é um fator determinante da estrutura de capital das empresas analisadas. Assim, as evidências não confirmam a existência de uma hierarquia de preferências por parte das empresas quanto às diversas fontes de financiamento, conforme propõe a teoria do Pecking Order.

Para confirmar esse resultado, o fator rentabilidade foi testado também na forma lucro líquido sobre vendas, tendo sido obtida, igualmente, uma relação não significante estatisticamente. Ressalte-se que o trabalho utilizou como variável explicativa a rentabilidade ajustada aos efeitos inflacionários.

Uma possível explicação para esse resultado é que, dadas as elevadas taxas de juros do nosso mercado, as empresas tomariam dívidas apenas quando os custos desses recursos fossem atrativos economicamente. Nessa hipótese, se a empresa tiver acesso a créditos com taxas de juros atrativas, ela se endividará mais, independentemente de possuir ou não geração de recursos interna por meio de lucros. Sob esse prisma, o principal fator que determinaria a estrutura de capital de uma empresa no Brasil seria o seu custo de capital de terceiros.

A relação entre endividamento e risco verificada no estudo foi oposta à hipótese estabelecida. Esperava-se uma relação negativa entre o risco da empresa e o seu volume de dívidas, tendo sido encontradas relações positivas em todos os indicadores de endividamento estudados, o que sugere que as empresas que têm maior risco de negócio são também as mais endividadas. Apesar de contrariar os fundamentos teóricos discutidos, o resultado confirma pesquisas anteriores realizadas no Brasil, como as de Gomes e Leal (2000), Sallum (2004) e Schmitt (2004).

Esse fato pode decorrer de alguma característica específica do mercado brasileiro, como, por exemplo, uma predisposição dos acionistas de investirem menos em empreendimentos de risco elevado, buscando, em contrapartida, maior proporção de capitais de terceiros, ainda que esses recursos sejam obtidos a custos financeiros maiores. De qualquer forma, percebe-se a necessidade de um aprofundamento das pesquisas em relação ao fator risco, inclusive com a operacionalização de outras variáveis.

O fator tamanho configura-se como determinante tanto para o endividamento total quanto para o endividamento de longo prazo, o que leva à confirmação das hipóteses estabelecidas. Em relação às dívidas de curto prazo, esse fator não se mostrou relevante. Os resultados confirmam a teoria dos custos de falência, indicando que as maiores empresas são mais endividadas e possuem maior proporção de dívidas de longo prazo, corroborando, também, a percepção de que as grandes empresas no Brasil têm maior acesso ao mercado de dívidas de longo prazo do que as pequenas empresas, sobretudo por meio das linhas do Banco Nacional de Desenvolvimento Econômico e Social (BNDES).

Quanto à proporção de ativos permanentes (composição dos ativos), esse fator apresentou relação positiva com o endividamento de longo prazo e negativa com o de curto prazo, confirmando as hipóteses de pesquisa. Entretanto, a relação negativa entre ativo permanente e dívidas totais foi contrária à esperada. Assim, as empresas com maior proporção de ativos permanentes têm menor nível de endividamento, porém, são mais endividadas em longo prazo do que em curto prazo.

Esse resultado parece se ajustar às características do mercado financeiro brasileiro, em que as linhas de crédito de longo prazo são restritas e normalmente direcionadas ao financiamento de investimentos específicos, mediante vinculação dos bens financiados como garantia para o credor.

O fator crescimento apresentou uma relação positiva com os endividamentos de longo prazo e total. Esse resultado indica que as empresas em crescimento são mais endividadas, sobretudo em longo prazo, o que leva à rejeição da hipótese de pesquisa. Essas evidências contrariam as teorias dos custos de falência e dos custos de agência, tendendo a confirmar a teoria das informações assimétri-

Tabela 7 Relações Esperadas e Observadas

\begin{tabular}{|c|c|c|c|c|c|c|}
\hline \multirow{2}{*}{ Fator } & \multicolumn{3}{|c|}{ Relação Esperada } & \multicolumn{3}{|c|}{ Relação Observada } \\
\hline & CIRC/AT & ELP/AT & EXIG/AT & CIRC/AT & ELP/AT & EXIG/AT \\
\hline Rentabilidade & - & - & - & NS & NS & NS \\
\hline Risco & - & - & - & + & + & + \\
\hline Tamanho & - & + & + & NS & + & + \\
\hline Composição dos Ativos & - & + & + & - & + & - \\
\hline Crescimento & - & - & - & NS & + & + \\
\hline Capital Aberto & - & - & - & NS & NS & NS \\
\hline
\end{tabular}


cas, segundo a qual as empresas em crescimento financiam seus novos investimentos por meio de dívidas como forma de sinalizar ao mercado que suas ações estão subavaliadas. Em sentido estrito, essa hipótese teria validade apenas para empresas de capital aberto.

Por fim, o fator tipo de capital não se mostrou significativo para a forma de financiamento das empresas. Dessa maneira, o fato de a empresa ser de capital aberto e poder financiar seus investimentos por meio da emissão de ações no mercado de capitais não é um fator determinante para a estrutura de capital das firmas analisadas.

Os fatores cujos resultados apresentaram maiores divergências em relação às pesquisas anteriores, realizadas no Brasil, foram rentabilidade e tamanho. Enquanto diversos trabalhos encontraram relações positivas para rentabilidade e não significantes para tamanho, os resultados do presente estudo indicam uma relação não significante para o fator rentabilidade e uma relação positiva para o fator tamanho. Assim, enquanto a rentabilidade não parece ser um fator determinante para a estrutura de capital, o tamanho da empresa é um aspecto que influencia a forma como ela se financia.

A divergência em relação ao fator rentabilidade possivelmente decorre da forma como a variável foi operacionalizada, uma vez que neste estudo foi considerada a rentabilidade líquida dos efeitos inflacionários, o que melhora significativamente a qualidade dos dados analisados. Por sua vez, a divergência no fator tamanho pode ser devido à composição da amostra de empresas utilizada. No presente estudo, o fator tamanho mostrou-se positivamente relacionado com o endividamento possivelmente em razão de ter sido analisada uma amostra maior de empresas, a qual inclui, também, as firmas de capital fechado, geralmente menores do que as companhias abertas utilizadas em estudos anteriores

empresas. Como a amostra utilizada inclui, igualmente, empresas que não têm papéis negociados no mercado de capitais, foi possível avaliar a relevância desse aspecto para a estrutura de capital das firmas. Além disso, a utilização de dados contábeis ajustados aos efeitos inflacionários levou a novas conclusões quanto ao fator rentabilidade.

Destaque-se que os fatores analisados neste trabalho explicam apenas parte das variações no endividamento das empresas, o que sugere que outras variáveis também influenciam a forma como as empresas se financiam no Brasil. Entre essas variáveis, podem existir fatores comportamentais específicos dos gestores, além de outros aspectos relacionados às características do ambiente econômico e institucional brasileiro não tratados explicitamente no estudo, como, por exemplo, em relação ao custo do capital de terceiros.

\section{Referências Bibliográficas}

ASSAF NETO, A.. Finanças corporativas e valor. São Paulo: Atlas, 2003.

BRADLEY, M.; JARREL, G.A.; KIM, E.H.. On the existence of an optimal capital structure: theory and evidence. Journal of Finance, v.39, n.3, Jul.1984.

COMISSÃO DE VALORES MOBILIÁRIOS. Relatório de companhias abertas. Disponível em: <http://www.cvm.gov.br >. Acesso em: 06 Dez.2004.

DeANGELO, H.; MASULIS, R.W.. Optimal capital structure under corporate and personal taxation. Journal of Financial Economics, v.8, n.1, Mar.1980.

DURAND, D.. Cost of debt and equity funds for business: trends and problems of measurement. In: Conference on Research on Business Finance. New York: National Bureau of Economic Research, 1952.

FERRI, M.G.; JONES, W.H.. Determinants of financial structure: a new methodological approach. Journal of Finance, v.34, n.3, Jun.1979.

GOMES, G.L.; LEAL, R.P.C. Determinantes da estrutura de capitais das empresas brasileiras com ações negociadas em bolsas de valores. In: LEAL, Ricardo P.C. et al. Finanças Corporativas. Coleção Coppead de Administração. São Paulo: Atlas, 2000.

HARRIS, M.; RAVIV, A.. The theory of capital structure. Journal of Finance, Chicago: American Finance Association, v.46, n.1, Mar.1991. 
JENSEN, M.; MECKLING, W.. Theory of the firm: managerial behavior, agency costs, and capital structure. Journal of Financial Economics, v.3, 1976. JOHNSTON, J.; DINARDO, J.. Econometric Methods. 4. ed. New York: McGraw-Hill, 1997.

KAYO, E.K.. Estrutura de capital e oportunidades de crescimento: uma análise dos determinantes do endividamento em diferentes contextos empresariais. São Paulo, 1997. Dissertação (Mestrado em Administração de Empresas) - Faculdade de Economia, Administração e Contabilidade, Universidade de São Paulo.

KLOCK, S.; THIES, F.. Determinants of capital structure. Review of Financial Economics, 1992.

MARTELANC, R.. Proposição e avaliação de política de hierarquização de fontes de financiamento sob restriçães de capital. São Paulo, 1998. Tese (Doutorado em Administração de Empresas) - Faculdade de Economia, Administração e Contabilidade, Universidade de São Paulo.

MILLER, M.H.. Debt and taxes. Journal of Finance, v.32, n.2, May 1977.

MYERS, S.C.. The capital structure puzzle. Journal of Finance, Chicago: American Finance Association, v.39, n.3, Jul.1984.

; MAJLUF, N.S.. Corporate financing and investiment decisions when firms have information that investors do not have. Journal of Financial Economics, Amsterdam: North Holland, v.13, Jul.1984.

MODIGLIANI, F.; MILLER, M.H.. The cost of capital, corporation finance, and the theory of investment. American Economic Review, Nashville: American Economic Association, v.48, n.3, Jun.1958.

Economic Association, v.53, n.3, Jun.1963

Corporate income taxes and the cost of capital: a correction. American Economic Review, Nashville: American

MOREIRA, M.M.; PUGA, F.P.. Como a indústria financia o seu crescimento: uma análise do Brasil Pós-Plano Real. Textos para Discussão 84, BNDES, Rio de Janeiro: 2000.

PEREIRA, S.B.C.. Análise da relação entre valor e alavancagem no mercado brasileiro. Anais do XXIV ENANPAD - Encontro Anual da Associação Nacional dos Programas de Pós-Graduação em Administração, Florianópolis, 2000.

PEROBELLI, F.F.C.; FAMÁ, R.. Fatores determinantes da estrutura de capital: aplicação a empresas de capital aberto no Brasil. RAUSP, São Paulo, v.37, n.3, jul-set.2002.

RAJAN, R.G.; ZINGALES, L.. What do we know about capital structure? Some evidence from international data. Journal of Finance, v.50, n.5, Dec.1995.

SALLUM, L.. Fatores determinantes da estrutura de capital: um estudo das empresas brasileiras. São Paulo, 2004. Dissertação (Mestrado em Administração de Empresas) - Faculdade de Economia, Administração e Contabilidade, Universidade de São Paulo.

SCHMITT, F.O.V.. Os determinantes da estrutura de capital das empresas brasileiras. São Paulo, 2004. Tese (Doutorado em Administração de Empresas) - Faculdade de Economia, Administração e Contabilidade, Universidade de São Paulo.

SCOTT, J.. A Theory of optimal capital structure. The Bell Journal of Economics, v.7, 1976.

TEDESCHI, P.. Estrutura de Capital: Uma Investigação sobre seus Determinantes no Brasil. São Paulo, 1997. Tese (Doutorado em Administração de Empresas) - Escola de Administração de Empresas de São Paulo, Fundação Getúlio Vargas.

TITMAN, S., WESSELS, R.. The determinants of capital structure choice. Journal of Finance, v.43, n.1, Mar.1988.

TOY, N.; STONEHILL, A.; REMMERS, L.; WRIGHT, R.; BEEKHUISEN, T.. A comparative international study of growth, profitability, and risk as determinants of corporate debt ratios in the manufacturing sector. Journal of Financial and Quantitative Analysis, Nov.1974.

WHITE, H.. A heteroscedasticity consistent covariance matrix estimator and a direct test of heteroscedasticity. Econometrica, v. 48, 1980.

WOOLDRIDGE, J.M.. Introductory Econometrics: a Modern Approach. 2 ed. Ohio: South-Western College Pub, 2003.

\section{NOTA - Endereço dos autores}

Universidade de São Paulo

FEA - Departamento de Contabilidade e Atuária

Av. Prof. Luciano Gualberto, 908 - prédio 3

São Paulo - SP

05508-900
Universidade de São Paulo

FEA - Departamento de Contabilidade

Av. Bandeirantes, 3900 - Monte Alegre

Ribeirão Preto - SP

14040-900 